\title{
The Social Construction of Power: Reflections Beyond Berger/Luckmann and Bourdieu
}

Cultural Sociology 2016, Vol. IO(I) 53-68 (C) The Author(s) 2015 Reprints and permissions: sagepub.co.uk/journalsPermissions.nav DOI: I0.1 I77/I7499755I56/5623 cus.sagepub.com

@SAGE

\section{Jochen Dreher}

University of Konstanz, Germany

\begin{abstract}
This paper emphasizes the specific theoretical potential of Peter L. Berger and Thomas Luckmann's The Social Construction of Reality for an analysis of the construction and constitution of power. In contrast to certain criticisms, as formulated for example by Pierre Bourdieu, which reproach the authors for being oblivious of power, it is shown that Berger and Luckmann's theoretical apparatus indeed offers the possibility to reconstruct established power structures as part of objective reality. Furthermore, the authors open up a distinct perspective from which to systematically analyze the subjective dimension of power constitution with reference to the subjective reality of the individual actor. We argue that the investigation of power inevitably needs to be based on the idea of the dialectical relationship of objective and subjective reality. Moreover, this paper shows that it is specifically the subjective dimension of power constitution based on systems of relevance that allows for an explanation of the resistance to established power structures on the part of the individual actor.
\end{abstract}

\section{Keywords}

power, social construction, social constructionism, Berger, Luckmann, legitimation, symbolic universe, phenomenology, Bourdieu, Schutz, theory of relevance, Marx, Weber, Durkheim

\section{Introduction}

Peter L. Berger and Thomas Luckmann's ground-breaking work The Social Construction of Reality (1989 [1966]) not only re-defines a materialistically based sociology of knowledge by founding a sociological theory on phenomenology and philosophical anthropology. It furthermore establishes a bridge between Emile Durkheim's structuralist sociology and Max Weber's interpretive sociology by demonstrating the necessity of taking into consideration the objective facticity ('social facts as things') and at the same time the

\section{Corresponding author:}

Jochen Dreher, Social Science Archive Konstanz, University of Konstanz, Box 35, D-78457 Konstanz, Germany.

Email: Jochen.Dreher@uni-konstanz.de 
subjective meaning of society. Berger and Luckmann describe the task of sociology of knowledge as the study of the social construction of reality; to be more precise, as the analysis of the social construction of the world within the dialectical relationship of objective and subjective reality. Parting from but reaching far beyond Alfred Schutz's phenomenologically oriented sociology, they establish a sociological theory with the potential to bridge the gap between subjectivism and objectivism.

Even though the concept of power is not specifically in the focus of Berger and Luckmann's work, it will be demonstrated that their social constructionist position particularly serves for an analysis of power related to objective social structures and at the same time depending on subjective constitution. ${ }^{1}$ This paper will illustrate the processes of power formation within the dialectics of objective and subjective reality, thereby rejecting the accusation of 'power oblivion' (e.g. Bourdieu, 1992) directed towards Berger and Luckmann's sociology of knowledge. It furthermore underlines the theoretical strengths of this standpoint for the explanation of the subjective dimension of power constitution, which offers the potential to confront and object to predominating power hierarchies.

\section{The Social Construction of Power}

Although no explicit concept of power is established in The Social Construction of Reality, several lines of argument consider the phenomenon of power as theoretically relevant, and the outline of a theory of power can be developed from this vantage point of social theory. For the analysis of power, Berger and Luckmann's differentiation between society as objective reality and society as subjective reality proves to be decisive. This theoretical distinction is specifically based on the reception of Durkheim's and Weber's sociological perspectives. The Durkheimian conviction that 'social facts' have to be considered 'as things' leads to the assumption that society does have objective facticity. In contrast to this view, Max Weber proposes that society is built up by activity that expresses subjective meaning (Berger and Luckmann, 1989 [1966]: 18). According to Berger and Luckmann, the two theoretical positions are not contradictory and have to be perceived in combination with each other. They argue: 'It is precisely the dual character of society in terms of objective facticity and subjective meaning that makes its "reality sui generis"' (1989 [1966]: 18, original emphases). It is from this link between Durkheim's and Weber's sociologies that Berger and Luckmann derive their research questions, asking how it is possible that subjective meanings become objective facticities or how human activity includes the capacity to produce a world of things? The inquiry of the 'reality sui generis' of society requires an investigation of the manner in which this reality is constructed. According to the authors, this is the genuine task of the sociology of knowledge.

Concurrent with Max Weber's individualistic methodological viewpoint, power is considered as the probability of one actor in a social relationship to carry out his or her own will even despite resistance (Weber 1978 [1920/21]: 53). Power is a universal element of human existence and it is present in all forms of social relationships. With reference to power as thematized in The Social Construction of Reality, the idea is decisive that objective reality is always connected to subjective reality, that subjective meaning is 
transferred into objective social facts that in turn determine the constitution of subjective reality. This systematic interconnection is what is described as a 'dialectical relationship between objective and subjective reality' (Berger and Luckmann, 1989 [1966]: chapters 2 and 3). Furthermore, this idea is related to what the authors describe as a 'dialectic between individual and society' (Berger and Luckmann, 1989 [1966]: 174). Society is formed by individual actors who produce society based on a subjective reality which guides their actions. At the same time, individuals are formed by society and its objectivations. As far as power is concerned, it is precisely objective reality which comes into focus, since power structures and power hierarchies are specifically seen as structural conditions of, for example, social stratification related to inequality.

It is the institutional world supporting social stratification, experienced as objective reality, which is perceived by individuals as social facticity. The institutional world was there before the individual's birth and it will be there after his or her death. History, which can be seen as the tradition of existing institutions, has the character of objectivity. We have to mention that Berger and Luckmann, following Arnold Gehlen's philosophical anthropology, apply a wide concept of institution and institutionalization. Institutionalization according to Berger and Luckmann is based on reciprocal typification of habitualized actions by types of actors. Any reciprocal typification of habitualized action is therefore an institution. The typifications constituting institutions are always shared by the members of the group and the individual members of the group are at the same time typified by the institution. The law, marriage, and the incest taboo are institutions relevant for members of specific groups; the group members need to comply with what the institutions demand from them (Berger and Luckmann, 1989 [1966]: 54).

Institutions as the product of human action represent historicity and social control; reciprocal typifications are built into a shared history, that is to say, they arise historically. Institutions are part of a historical process and in their functioning can only be understood according to this constituting process. When institutions come into existence, they control human conduct by setting up patterns of conduct; they predefine possibilities for individuals to act. This primary form of social control can be considered as the preliminary form of power, which is exercised by the sole existence of the institution governing reciprocal action of the members of a group. As a secondary effect, specific mechanisms of sanctions are established when individual actors do not completely fulfill the demands of action which are prescribed by the institution (cf. Berger and Luckmann, 1989 [1966]: 55). Other members of the social group affected by the institution observe those who do not accept rules and laws and are able to implement sanctions against the ones who step out of line. Institutions produce social control through action constraints that are imposed on the individuals affected by the institution.

Specifically relevant for the discussion of power is the idea that institutions as historical and objective facticites for individuals exist as undeniable facts. Institutions therefore externally exist in a certain way independently of the individual. They are objectified and persist from generation to generation and they are able to resist and evade attempts to change them. They have coercive power over human beings, 'both in themselves, by the sheer force of their facticity, and through the control mechanisms that are usually attached to the most important of them' (Berger and Luckmann, 1989 [1966]: 60). The social world with its institutions may be opaque and inscrutable for the individual actors, but this does 
not affect its objectified existence. Even though the institutional world transcends the individual, it is 'humanly produced, constructed objectivity' (1989 [1966]: 60). Through the externalization of human products created in processes of action and interaction, these products - institutions, cultural artifacts, etc. - obtain the character of objectivity; the process of externalization leads to what is considered 'objectification' (Versachlichung) in the Hegelian and Marxian tradition. The social world is experienced by human beings as an objective world, which does not mean that it thereby acquires an ontological status independent of the human activity that produced it. This reflection is the basis for the idea that the relationship between human beings as producers and the social world as their product, as Berger and Luckmann argue, 'is and remains a dialectical one' (1989 [1966]: 61). They establish the conceptual triad of 'externalization,' 'objectification,' and 'internalization.' The concept of 'internalization' refers to the process of retrojection of the social world into the subjective consciousness of the individual which is achieved in socialization. The three dialectical moments of social reality are fundamentally related to each other and each of them represents an essential character of the social world. As the authors describe it: 'Society is a human product. Society is an objective reality. Man is a social product.' (1989 [1966]: 61). With reference to the power phenomenon, we argue that power differences and power hierarchies within societies and social groups supported by their institutions are a human product, because they are established in human activity. Manifest power hierarchies appear as part of the objective world and are perceived as belonging to the objective reality of society. In the process of socialization human beings internalize and incorporate objectively established power structures; their subjective reality is formed with reference to knowledge systems and material preconditions that are predefined by established power structures. It will be demonstrated that the conception of a dialectical relationship between objective reality and subjective reality specifically serves for the analysis of the social construction of power. To that end, we will reconstruct the discussion of the power phenomenon in The Social Construction of Reality.

\section{Power and the Social Construction of Reality}

\section{Legitimation and Power}

The concept of power is considerably important for the description of society as objective reality, especially when the term 'legitimation' gets introduced. Legitimation is seen as 'second order' objectivation of meaning, because it produces new meanings to integrate and support those meanings that were given to established institutions.

The function of legitimation is to make objectively available and subjectively plausible the 'first order' objectifications that have been institutionalized. (Berger and Luckmann, 1989 [1966]: 92)

Legitimization starts when on a first level a system of linguistic objectifications of human experience is transmitted. The second level of legitimation refers to theoretical propositions in a rudimentary form, such as proverbs, moral maxims and wise sayings, pragmatically related directly to concrete actions. On the first two legitimation levels, rudimentary forms of power relations based on traditions of specific social groups are 
constituted. The next level, the third level, legitimates an institutional sector with a differentiated particular body of knowledge. Specialized legitimation theories based on a particular knowledge of experts are applied to support an institution; specialized knowledge in this case is used to exert power over those who are affected by the institution. With respect to the issue of power, the following level is significant; on the fourth level of legitimation, 'symbolic universes' as bodies of theoretical tradition integrate different provinces of meaning and comprise the institutional order in its totality through symbolization, through symbolically established meanings that transcend our everyday experience. Here the authors follow Alfred Schutz's theory of the symbol, which argues that everyday transcendent realties - political worlds of ideas, religious belief systems, scientific paradigms, etc. - are established through symbols as specific forms of signs. Symbols are used in everyday communication within the pragmatic world of everyday life to 'appresent,' to make co-present everyday transcendent ideas, for example the ideas of 'solidarity,' 'liberty,' and so on (Schutz, 1962 [1955]: 329-356; see also Dreher, 2003).

\section{The Power of Symbolic Universes}

As far as symbolic universes are concerned, the pragmatic dimension of legitimation is transcended and the legitimation takes place by means of symbolic totalities that cannot be experienced in everyday life. Of importance here is the fact that symbolic universes not only refer to one institutional sector with specified knowledge; 'all the sectors of the institutional order are integrated in an all-embracing frame of reference' (Berger and Luckmann, 1989 [1966]: 96), which constitutes a meaningful universe of symbolic signification in which all human experiences 'can now be conceived as taking place within it' (1989 [1966]: 96, original emphasis). The concept of symbolic universes brings together the two different aspects of social reality, namely that it is perceived as objective as well as subjective reality. The symbolic universe according to Berger and Luckmann is conceptualized as a 'matrix of all socially objectivated and subjectively real meanings' (1989 [1966]: 96, original emphasis). The entire historical society, as well as the individual, is constituted within, and is therefore part of, this universe.

The concept of power in The Social Construction of Reality appears specifically related to the problem of universe-maintenance based on conceptual machineries which are the products of social activity. The argument underlines that the success of particular conceptual machineries - examples are symbolic systems such as mythology, theology, philosophy and science - is related to the power of those who operate these machineries, those belonging to a leading class who are propagating their specific worldview (i.e. an ideology). The symbolic universe and the predominant worldview, as Karl Marx would argue, are the ones propagated by the leading elite of the powerful. In 'The German Ideology', he argues that ' $[\mathrm{t}]$ he ideas of the ruling class are in every epoch the ruling ideas: i.e., the class which is in the ruling material force of society is at the same time its ruling intellectual force' (Marx, 1976 [1845/46]: 59, original emphases). This means that the leading class has the means for material production at its disposal and is therefore also able to control the means of mental production. Marx deduces from this reflection that ' $[\mathrm{t}]$ he ruling ideas are nothing more than the real expression of the dominant material 
relations, the dominant material relations grasped as ideas' (1976 [1845/46]: 59). This position gets integrated into Berger and Luckmann's dialectical conception.

Obviously, the confrontation of alternative, differing symbolic universes depends on the problem of power, because diverging definitions of reality on the one hand have to be brought into coherence within society. When two societies with conflicting universes are confronted with each other, both of them are forced to develop conceptual machineries that are designed and fitting for the symbolic universe which needs to be legitimated. Which of the universes becomes prevalent, following Berger and Luckmann, depends on the other hand more on power than on the theoretical ingenuity of the legitimators: ' $\mathrm{He}$ who has the bigger stick has the better chance of imposing his definitions of reality' (Berger and Luckmann, 1989 [1966]: 109). This means that the position of power already assumed by an elite of persons, for example of governing politicians, is decisive for an implementation of a certain symbolic universe through conceptual machineries. The power of interpretation of these elites results from their established power position which gives them the acceptance to formulate a worldview. This reflection is strongly related to what Pierre Bourdieu describes as 'authorized language'; the power of words and worldviews is 'nothing other than the delegated power of the spokesperson' (Bourdieu, 1991a: 107 , original emphasis). It is not of importance how convincing the discourse of the powerful, of those who propagate a symbolic universe, may be; the power is not part of the speech act, but it comes from outside and it is given to the elites by structural preconditions. The Protestant reformer Martin Luther serves as an example at this point of the argumentation; as priest and professor of theology, expert of the institution of the Roman Catholic Church, he challenged and contested the predominating symbolic universe of his time by propagating a counter-perspective. Even though he questioned the doctrine represented by the Pope, he was able to appropriate power despite his excommunication from the Catholic Church.

Berger and Luckmann's standpoint can be explained and supported with reference to forms of power described by the German sociologist Heinrich Popitz, who develops ideal types of power such as 'power of action,' 'instrumental power' and 'authoritative power.' Power of action is exercised on the basis of bodily superiority or violence depending on the potential vulnerability of human beings (Popitz, 1992: 23-26). The state which has the monopoly of legitimate use of force at its disposal therefore has the better chance to propagate a certain symbolic universe. When it comes to instrumental power, human beings are permanently declared to be an instrument of foreign will. This form of power results from the ability to give and take (resources, affection, knowledge, etc.) and the possibility to give punishment or gratification. It is based on the assumption that the powerful have the plausible potential possibility to punish and gratify other people. No power of action through violence has to be applied for instrumental action; this form is the typical everyday form of power of threatening and promising, the conventional enforcement against foreign powers. All permanent exercise of power is based on this form of instrumental power (Popitz, 1992: 26-29). Of course, powerful elites can apply this form of power based on threatening and promising to secure the symbolic universes they themselves propagate; instrumental power serves to protect the established worldview and is accompanied by a specific power of interpretation. Authoritative power functions through the voluntary, consenting agreement of those who are in an inferior situation (i.e. subordinates). It explains the influence of experts propagating their theory and their symbolic universe, which is also based on a knowledge deficit of those who are in a less powerful situation. 


\section{Exertion of Power through Experts}

Power is equally important when the problem of rival coteries of experts who struggle for universe-maintaining legitimation arises. It could be argued that the theories developed by experts always need to be tested under pragmatic circumstances by practitioners and the theory that better serves praxis becomes prevalent. Theoreticians are forced to substitute abstract argumentation for pragmatic testing. But theoretical argumentation does not necessarily include grounds for pragmatic success; some arguments are convincing for some persons, for others they are not; or it might not even matter which content the argumentation offers. Therefore, as Berger and Luckmann argue, 'various other sturdier supports for the frail power of the mere argument' (1989 [1966]: 119) are applied by the experts. The strategy is to employ 'armed might to enforce one argument against its competitors' (Berger and Luckmann, 1989 [1966]: 119). Again the argument is made that 'power of action', 'instrumental power', and 'authoritative power' are exercised to establish and protect symbolic universes and the theoretical pillars that support them. According to the authors, 'definitions of reality may be enforced by the police' (1989 [1966]: 119). It is not necessarily the case that such definitions pushed by authoritarian entities are less convincing than those definitions accepted voluntarily: '[P]ower in society includes the power to determine decisive socialization processes and, therefore, the power to produce reality' (Berger and Luckmann, 1989 [1966]: 119, original emphasis). This reflection demonstrates a decisive component of the notion of power at the interface of objective and subjective reality. It shows perfectly the relevance of subjective reality since the socialization process is determined by objectively given symbolic universes that are imposed on individual actors by the powerful. They are able to control the knowledge transfer that the individuals receive in their socialization; subjective reality is therefore determined by objectively established patterns of thought which are pre-structured by power relations.

This idea is strongly related to what Bourdieu later considers as the functioning of 'symbolic power', which is specifically based on the subjective perception of the social world. In a way similar to Berger and Luckmann, Bourdieu argues that the social world is the product of a 'double structuring': with respect to the objective world, it is socially structured 'because the properties attributed to agents or institutions present themselves in combinations which have very unequal probabilities' (Bourdieu, 1990a: 31). It is characterized by objectively established power structures such as concrete expressions of social inequality. As far as the subjective dimension of the social world is concerned, that perception is structured according to models of perception and evaluation which express symbolic power relations as far as they are recognized within a specific social group. Symbolic power on the one hand is based on symbolic capital - economic and cultural capital approved by social agents - that is transferred to those who received recognition in order to enforce recognition themselves. On the other hand, the effectiveness of symbolic power depends on how a vision or worldview of a certain social group is founded on a specific reality: 'Symbolic power is a power of creating things with words. It is only if it is true, that is, adequate to things, that a description can create things' (Bourdieu, 1990b: 138). What creates the power of the words is actually a power with the potential to maintain or subvert the social order; it is based on the belief in the legitimacy of words 
and of those who utter them; needless to say, the words alone cannot create such a belief (Bourdieu, 1991b: 170).

With respect to Berger and Luckmann's viewpoint, the propagated and established symbolic universe receives effectiveness and starts to function due to the fact that individuals in their socialization were pre-figured by ideas, thought systems and categories prescribed by the 'ruling class' of a society. The abstract theories which sustain symbolic universes are validated more by social support than by empirical evidence. Theories function because they work, and they work because they are said to work and therefore they are convincing. They function because they have become standard in the form of knowledge taken for granted in a particular society.

If the discussion concentrates on the rivalry of different symbolic universes, the importance of the social-structural base of the competition between rival definitions of reality becomes apparent. Who wins the competition is of course to a certain degree determined by the development of the base. Marxist ideas about the significance of the base related to the success of propagations of reality can be identified at this point of the argumentation. The different interests of the competing experts determine the form and substance of the theories they develop; their material interests influence the expression of the theories.

There is the possibility that a symbolic universe establishes a monopoly, which means that a single symbol tradition and theoretical conception maintains the universe. Practically all members of a society recognize and share the worldview connected to the symbolic universe - propagated by its experts - and there are no competitors to challenge the predominant position. For the monopolistic reigning of the symbolic universe and its expert administrators, it is the case that a unified power structure sustains the dominating worldview: 'Those who occupy the decisive power positions are ready to use their power to impose the traditional definitions of reality on the population under their authority' (Berger and Luckmann, 1989 [1966]: 121). If competing conceptualizations of the universe emerge, they either can be liquidated as soon as they occur, or they can be integrated and 'merged' with the dominant tradition. As far as external divergent competing definitions of reality are concerned, they can be conceptually and socially segregated as appropriate to strangers and therefore made irrelevant for one's own community. This opens the possibility to establish a fairly friendly relationship with the strangers holding a diverging worldview. These monopolistic conceptions of a symbolic universe presuppose a high degree of social-structural stability, and they are at the same time stabilizing. 'Traditional definitions of reality inhibit social change. Conversely, breakdown in the taken-for-granted acceptance of the monopoly accelerates social change' (Berger and Luckmann, 1989 [1966]: 122). Berger and Luckmann propose a profound affinity between those with an interest in maintaining established power positions, and those experts involved in administering monopolistic traditions of universe-maintenance. That is why conservative political forces rather support the monopolistic claims of universal experts, for example those of the Christian church in the medieval period, whose forms of organization are more likely to be politically conservative. Furthermore, it has to be highlighted that when a particular definition of reality is attached to a concrete power interest, it is called an 'ideology' (Berger and Luckmann, 1989 [1966]: 123). 
The argument considered with the notion of 'society as objective reality' comes to the final conclusion that institutions as well as symbolic universes are legitimated by living individuals with concrete social locations and concrete social interests. Experts dedicated to the legitimation of symbolic universes may function as justifiers of the status quo; yet they can also appear as revolutionaries struggling for the legitimation of their diverging worldview with a specific power of interpretation. And social change - e.g. the product of a revolution - can be based on the realization of ideas in history; it always has to be understood in a dialectical relationship to the 'history of ideas.' In their synthesis of Durkheim's, Weber's and Marx's programs, the authors argue that all symbolic universes and all legitimations are human products and their existence is based on the lives of concrete individuals (Berger and Luckmann, 1989 [1966]: 128); one cannot imagine them independently of the empirical expressions of their lives.

\section{Alleged 'Oblivion of Power'}

The reconstruction of the reflections on power in The Social Construction of Reality demonstrates the significance of the power concept with respect to the development of a sociology of knowledge. Society as objective reality with its institutions and symbolic universes is characterized by established power structures. The social world with its established power hierarchies is a product of human activity; it is constructed in processes of social action. Society as subjective reality is formed through internalized and shared stocks of knowledge which include the categories of structuration of the world related to power. Individual perception and experience are in major parts determined by power structures. The decisive point in this conception is the fact that power is constructed within the dialectical relationship of objective and subjective reality.

The reproach of an alleged 'oblivion of power' directed at Berger and Luckmann is therefore incomprehensible. And it is specifically Pierre Bourdieu who - as we have demonstrated - develops a quite similar theoretical conception with reference to the objective and subjective dimension of society, and did it some decades after the publication of the Social Construction, while also incorporating the Marxian standpoint on ruling classes and the exertion of power. Bourdieu discovers the alleged problem of a 'naturalization of the familiar world' with respect to the work of Alfred Schutz and the 'neo-phenomenological tradition' that he associates with the name Peter L. Berger and certain forms of ethnomethodology. This 'naturalization of the familiar world' is supposed to be accompanied by the necessary side effect that 'the conditions of possibility and reflection on the symbolic field of power are condemned to obscurity' (Bourdieu, 1991b: 276-277). This perspective according to Bourdieu reproduces in sociological terms the fact that the familiar world is 'taken for granted' or perceived as natural. The acceptance of this presupposition - he argues - omits the social conditions of the possibility of the doxic experience of the world - as explained by Edmund Husserl - and, in particular, the doxic experience of the social world; that is, the experience of the social world as being self-evident or 'taken for granted,' in Schutz's terms (Bourdieu, 1991b: 276-277, Endnote 3). Therefore, Bourdieu mentions the necessity to sociologize the phenomenological analysis of doxa. He thinks that phenomenology does not ask how the 'taken-for-grantedness' of the familiar world comes into existence as a conditioning 
factor that makes social experience possible. Phenomenologists, according to Bourdieu, fail to ask why the social world is taken for granted by the natural attitude, taken as 'doxa', as unquestioned belief; they do not - so he argues - reflect upon the genesis of the natural attitude (Endress, 2005: 59).

Due to this supposed epistemological problem of phenomenology, Bourdieu poses the question of whether the contours of the life-world in the 'natural attitude' that are given as 'taken-for-granted' in everyday life are by themselves universal boundaries of the social world. Or do they have a history of their own which therefore sociology has to take into account? Bourdieu's sociology pursues the objective of analyzing this history, the historically-situated pre-conditions of the life-world, to understand the 'forgotten fields of power' involved in the constitution of the life-world. The aim is to discover the unthought categories of thought limiting the thinking and pre-determining what is actually thought. To sum up, Bourdieu criticizes phenomenologically-oriented sociology for its supposed lack of any analysis of knowledge-generating processes as always structured by power. ${ }^{2}$ Phenomenologists accordingly would obliterate the presuppositions of their thought, the social conditions of possibility of the scholastic point of view and the unconscious dispositions that produce unconscious theses (Endress, 2005: 58, 60). Apparently forgotten are the subjectified 'dispositions' that include categories and hierarchies of power, since they were constituted dependent on objectively established concrete expressions of power. We argue that when it comes to the discussion of the 'unknown' field of knowledge active in everyone's consciousness, Berger and Luckmann would not speak of the 'unconscious', but of sedimentations of experience and of habitualization. The subjective stock of knowledge as a product of sedimentation is characterized by social differentiation and therefore power structuration. Habitualization possesses the fundamental function of acceleration for the deciding and accomplishing of actions through 'discharge' (Entlastung). Habitualized action is the basis for the development of ideas and innovation. Routinization of action requires a typification of events, which depends on the relevance of pending tasks of action. Habitualization results from individual experiences of action and corporeal skills that obtain the status of habitualized knowledge. Commonly shared habitualizations and typifications may be released from the patterns of subjectivity of those individual actors who developed them; habitualizations are the foundation of institutions (Knoblauch, 2003: 190-198) and therefore also the foundation of an objectified social order with structures of power and domination.

What becomes obvious at this point is the fact that Bourdieu as well as Berger and Luckmann perceive the social world in its objectified as well as subjectified expressions. Bourdieu rejects a purely objectivist as well as a purely subjectivist standpoint and propagates reflection upon one's own epistemological standpoint. A reflection on the validity claims of a scientific description is essential, as is a reflection on the limits of the knowledge acquired; scientific practice includes the requirement to question itself. Only in this way is it possible to avoid the 'illusion of immediate knowledge' (subjectivism) and also the 'illusion of absolute knowledge' (objectivism) (Bourdieu, 1990b: 125). It becomes obvious that it is specifically Berger's and Luckmann's sociology of knowledge which manages to bridge the 'epistemological gap' between subjectivism and objectivism, since the analysis of the social world concentrates on the dialectical relationship of subjective and objective reality. This social constructionist perspective decidedly focuses on 
the investigation of the process of generating knowledge and of its origins, and, as will be demonstrated, it takes into consideration the connection of action and meaning as well as the relevance structure of knowledge.

Bourdieu's solution for overcoming the gap between objectivism and subjectivism can be found in the concept of habitus, which is seen as a disposition based on a specific stock of knowledge which structures our experience and action. The habitus has to be understood as an endless capacity to engender products such as thoughts, perceptions, expressions, or actions which are limited by historically- and socially-situated conditions of their production. It secures 'the conditioned and conditional freedom' (Bourdieu, 2010 [1972]: 95) which forms the basis of our actions and functions as a precondition for them. The habitus is seen as an individually incorporated generative dynamic structure formed by objective power structures. Yet this is rather a static concept that is less suitable to describe the subjective expression of the social world with its dynamic related to social action. The concept of habitus, situated at the interface of objective and subjective reality, is able to explain the reproduction of power structures, but does not provide a theoretical framework which could explain the processes by which actors struggle against and transform established power structures (Dreher, 2013: 114). Parting from Berger and Luckmann's conception of social reality, it will be shown that the relevance structure of the individual actor provides the specific theoretical potential to explain actions that oppose and transform existing power structures.

\section{The Subjective Dimension of Power Constitution}

As far as the development of a theory of power based on Berger's and Luckmann's reflections in The Social Construction of Reality is concerned, a specific theoretical potential results from their focus on the constitution of subjective reality as part of the social world. The strength of this approach lies in a description of the interplay of objective and subjective reality from the perspective of methodological individualism. The individual actor involved in producing and objectifying the social world is the focus of the argumentation. The subjectivity of the individual actor involved in processes of action is decisive for this viewpoint. Power is not only part of the argumentation with respect to the objectivity of the social world; it is also involved in processes of action related to the subjectivity of the individual. And we are not just focusing on habitus as a subjectively generated precondition of action prescribed by power structures. From the perspective of a constructionist theory of knowledge, we propose to investigate the subjective dimension of power constitution in its relation to the world of everyday life and structures of relevance of the individual. Specifically the knowledge of everyday life as structured by systems of relevance forms the basis for the subjective dimension of power constitution.

What is taken for granted as knowledge in society is presumed to be coextensive with what is knowable, as Berger and Luckmann argue, and it provides the framework within which anything will come to be known in the future. Taken-for-granted knowledge in society is learned in the course of socialization, and it mediates the internalization within individual consciousness of the objectivated structures of the life-world. The dialectic of 
the social world becomes explicit; knowledge coordinates the externalization that produces an objective world. Knowledge is involved in the objectification of this world through language and the cognitive apparatus based on language; knowledge orders the world into objects to be apprehended as reality. 'It is internalized again as objectively valid truth in the course of socialization' (Berger and Luckmann, 1989 [1966]: 66). Knowledge about society is therefore, on the one hand, a realization in the sense of apprehending the objectivated social reality; on the other hand, it is the outcome of the process of constantly producing this reality. This knowledge, the social stock of knowledge is transmitted from generation to generation, learned as objective truth in the course of socialization, and thus internalized as subjective reality. This reality has the power to shape the individual, his or her biography, personality and his or her identity (Berger and Luckmann, 1989 [1966]: 67). It will now be demonstrated how within the dialectical relationship of objective and subjective reality power not only functions as part of the objectifications of the social world. It will be argued that the subjective dimension of power constitution arises based on the knowledge of the world of everyday life with its respective structure of relevance.

Berger and Luckmann, in their first chapter on 'The Foundations of Knowledge in Everyday Life,' underline the relevance structure of our knowledge of everyday life. Some of the relevances are determined by immediate pragmatic interests of mine, others by my general situation in society (Berger and Luckmann, 1989 [1966]: 45). The authors follow Schutz's reflections on the problem of relevance, which we need to apply and expand in order to develop an explanation for the subjective constitution of power. The notion of 'relevance' specifically serves to explicate power at the interface of objective and subjective reality, since it functions as a regulative principle of reality construction. It coordinates the knowing and experiencing of objects and it serves the individual actor for the definition of the situation (Nasu, 2003: 91). The social world possesses a structure of meaning and relevance for all those who live, think, and act in it (Schutz, 1962 [1953]: 5-6). The social world with its power structures is already pre-interpreted and contains a stratification based on typifications and symbolizations that are unquestionably given to the members of the social group. The knowledge of the everyday life-world of the individual is structured in relation to degrees of familiarity and acquaintance, and it is relative to his or her biographical situation; the knowledge of the social group is relative to its respective historical situation.

The relevance concept enables us to investigate the subjective motivation of the individual entering into processes of action. The theory of relevance is based on the assumption that the individual actor living in the world experiences him- or herself in a certain situation which - following the Thomas theorem (Thomas and Thomas, 1928: 572) - has to be defined by him- or herself. The definition of the situation includes two decisive components: the first is the result of the ontological structure of the pre-given world, and the other is defined by the actual biographical state of the individual. The first component cannot be changed by the individual and determines the imposed systems of relevance that are not connected with his or her chosen interests and do not originate in acts of our discretion; there is no possibility to change them. The second component determines our intrinsic systems of relevance that are related to our chosen interests, established by our spontaneous decision to solve a problem by our thinking, to attain a goal by our action, 
etc. (Schutz, 1964 [1946]: 126-127; 1970: 26-35). The theory of relevance with its reference to the subjectivity of the individual actor allows us to establish a bridge between subjective motivation and objective knowledge structures imposed on the individual (Dreher and López, 2015: 215-216). Power structures as part of the objective reality of society are implemented in the stock of knowledge of the individual specifically in the form of imposed systems of relevance. The subjective motivations of the individual actor depend on imposed and intrinsic relevances; they are simultaneously the starting point for challenging the objectively-given determinations of imposed power structures. If we return to our example of the reformer Martin Luther, we see that he developed on the basis of intrinsic relevances the motivation to restructure the Roman Catholic Church of his times, questioning his own imposed relevances by which he was socialized according to the dominant power structures of Catholic doctrine. At the same time, Luther legitimated his protest against the established Church by arguing - e.g. at the trial of Worms - that he acted following 'the word of God', which in this case can be interpreted as an imposed relevance structure.

The specific potential of the theory of relevance lies in the possibility to illuminate determination and freedom of action and, in this sense, subjection to power structures as well as resistance to them. Schutz establishes three ideal types of relevance which, as we argue, serve to explicate the subjective dimension of power constitution: he introduces 'motivational', 'thematic', and 'interpretational relevances'. As far as motivational relevances are concerned, they explain the subjectively experienced motives in order to define the situation and characterize the interests that are pre-given and pre-structured by the objective world. Imposed categories of power enter into the subjective stock of knowledge and are expressed by motivational relevances. Based on these relevances, the individual defines the situation thinkingly, actingly, and emotionally, to be able to come to terms with the world. Motivational relevances result from our taken-for-granted knowledge, and they are determined by a pre-given world of meaning and the symbolic universes as part of the objective reality of the social world. They are based on routinized action and they are not questioned by the individual.

The second ideal type of thematic relevances differs from the first one, because specifically what is taken for granted is not focused by attention. The unknown and the unfamiliar become relevant, because the taken-for-granted proves to be questionable and uncertain. The actual stock of knowledge does not provide the necessary options for problem solving within the course of action, which is why our knowing consciousness needs to focus on a new thematically relevant topic. The creative acquisition of additional knowledge becomes important, because the current explanations and existing worldviews do not offer consistent possibilities to solve a situation of action. Thematic and motivational relevances can be either imposed or intrinsic, but intrinsically motivated thematic relevances contain the subjective potential to confront or challenge pregiven structural conditions, for example situations experienced as unequal. In this way, objectively imposed power structures can be contested on the basis of thematic relevances which reject taken-for-granted imposed knowledge and initiate action against it. A standpoint for a critique of social reality based on the subjectivity of the individual actor becomes obvious here (Dreher and López, 2015: 217). This process of confrontation with, and resistance against, established power structures is delineated by Berger 
and Luckmann in describing legitimizing experts who appear as revolutionary ideologists who argue against the predominant symbolic universe of the status quo. The Protestant reformer Martin Luther deliberately challenged the established symbolic universe and doctrine of the Catholic Church, encountering specific problems, for example related to the authority of the Pope and the indulgence system.

Interpretational relevances are the outcome of former thematic relevances. When a specific solution is found for an occurring problem within the course of action, it can be established as a typical solution for frequently occurring problems of a similar expression. They are biographically and ontologically determined and have their origins in motivational relevances. Different interpretations of social reality - e.g. religious interpretations, magical understandings, or natural scientific explanations, etc. - may be used to propagate new perspectives and solutions to problems. Legitimations of power, if thematically relevant, can therefore be diversified and the individual actor has the freedom to accept or confront biographically, culturally, or socially determined interpretational relevances that are 'imprinted' by power structures. Martin Luther's Protestantism can be perceived as the result of the establishment of a symbolic counter-universe as the outcome of his own interpretational relevances. Diverging from official teachings, he formulated his idea of Christianity based on God's grace and on faith in Jesus Christ as the redeemer from sin. Luther's revolutionary or reformatory success is explained through the dynamic interplay of relevances that allow the subjective dimension of power constitution to be reconstructed. Obviously, Luther was supported by the real factor of protection by the worldly power of Elector Frederick, when he needed refuge at the Wartburg. To sum up, it can be argued that the theory of relevance offers a model to explain the rejection of religiously, magically, or scientifically legitimated power structures.

\section{Conclusion}

Berger and Luckmann's constructionist sociology of knowledge offers decisive ideas and conceptual tools to establish a theory of power. In contradiction to Bourdieu's assumption, they do not remain in what is labeled as 'subjectivism', but instead develop a theoretical conception which 'bridges' the 'epistemological gap' between objectivism and subjectivism, through the investigation of the dialectic of the objective and subjective reality of the social world. Objective reality expresses manifest power structures that are internalized by individual actors and become part of the subjective reality. Prestructured subjective reality based on the subjective stock of knowledge, including categories of power, interferes in human production and externalization, which leads to the objectifications of the social world. This constructionist conception of power offers a theoretical framework to explain the power of, and domination by, elites propagating their symbolic universes independently of the substantial content of these worldviews. The criticism of an alleged 'oblivion of power' proved erroneous with respect to Berger and Luckmann's theoretical conception, since their particular sociology of knowledge offers the possibility to analyze the 'forgotten fields of power' through focusing on the genesis and relationality of knowledge. As far as the problem of power constitution related to the subjective reality of the individual is concerned, the deficiency of Bourdieu's static concept of 'habitus' becomes obvious, because individual motivation and action 
processes structured by power cannot be fully captured by it. Following and also going beyond the arguments offered in The Social Construction of Reality, we replace the concept of habitus with the concept of relevance, arguing that the subjective dimension of power constitution can be explained by the interplay of imposed and intrinsic systems of relevance. The notion of relevance includes the theoretical potential to elucidate how the subjectivity of the individual actor interferes and steers resistance against opposed objectified power structures. Based on thematic relevances, new solutions for problems of action are formulated; revolutionary ideas are expressed against the status quo of established symbolic universes and their power elites. Counter-ideologies are implemented as interpretational relevances with the capacity to redefine the existing power hierarchies of a society. To sum up, and loosely based on Berger and Luckmann (1989 [1966]: 61), we argue: Power structures are a human product. Power is perceived as objective reality. Human beings are a social product formed with relation to power.

\section{Acknowledgements}

I specifically would like to thank the two reviewers whose very substantial comments were the basis for a fruitful improvement of the paper.

\section{Funding}

The author disclosed receipt of the following support for the research, authorship, and/or publication of this article: This essay was supported by funds made available by the Cultural Foundations of Social Integration Center of Excellence at the University of Konstanz, established in the framework of the German Federal and State Initiative for Excellence.

\section{Notes}

1. The concept of 'constitution' refers to subjective processes of power formation and is derived from phenomenological assumptions which focus on the activities of the subjective consciousness.

2. Bourdieu's reflections are specifically based on the terminology of Michel Foucault, who argues that 'power' functions through knowledge discourses that are charged with a certain degree of truth. As Foucault states, 'there is no power relation without the correlative constitution of a field of knowledge, nor any knowledge that does not presuppose and constitute at the same time power relations' (Foucault, 1977: 25).

\section{References}

Berger PL and Luckmann T (1989 [1966]) The Social Construction of Reality: A Treatise in the Sociology of Knowledge. New York: Anchor Books.

Bourdieu P (1990a) The Logic of Practice. Cambridge: Polity Press.

Bourdieu P (1990b) Social space and symbolic power. In: Bourdieu P. In Other Words: Essay Towards a Reflexive Sociology. Cambridge: Polity Press, pp. 123-139.

Bourdieu P (1991a) Authorized language: The social conditions for the effectiveness of ritual discourse. In: Thompson JB (ed.) Language and Symbolic Power. Cambridge: Polity Press, pp. 107-116.

Bourdieu P (1991b) On symbolic power. In: Thompson JB (ed.) Language and Symbolic Power. Cambridge: Polity Press, pp. 163-170 and endnotes pp. 276-277. 
Bourdieu P (2010 [1972]) Outline of a Theory of Practice. Cambridge: Cambridge University Press.

Dreher J (2003) The symbol and the theory of the life-world: The transcendences of the life-world and their overcoming by signs and symbols. Human Studies 26(2): 141-163.

Dreher J (2013) Reflections on a phenomenology of power. Schutzian Research V(1): 103-119.

Dreher J and López D (2015) Subjectivity and power. Human Studies 38: 197-222.

Endress M (2005) Reflexivity, reality, and relationality: The inadequacy of Bourdieu's critique of the phenomenological tradition in sociology. In: Endress M, Psathas G and Nasu H (eds) Explorations of the Life-World: Continuing Dialogues with Alfred Schutz. Dordrecht: Springer, pp. 51-74.

Foucault M (1977) Discipline and Punish: The Birth of the Prison. New York: Pantheon Books.

Knoblauch H (2003) Habitus und Habitualisierung: Zur Komplementarität von Bourdieu und dem Sozialkonstruktivismus. In: Rehbein B, Saalmann G and Schwengel H (eds) Pierre Bourdieus Theorie des Sozialen: Probleme und Perspektiven. Konstanz: UVK, pp. 187-201.

Marx K (1976 [1845/46]) The German Ideology. In: Marx K and Engels F, Collected Works, Vol. 5. Marx and Engels: 1845-47. New York: International Publishers.

Nasu H (2003) A Schutzian approach to the problem of equality-inequality. In: Chan-Fai Cheung $\mathrm{CF}$, Chvatik I and Copoeru I (eds) Essays in Celebration of the Founding of the Organization of Phenomenological Organizations. Available at: http://opo-phenomenology.org/ (pp. 1-14, accessed 20 October 2015).

Popitz H (1992) Phänomene der Macht. Tübingen: Mohr.

Schutz A (1962 [1953]) Common-sense and scientific interpretation of the social world. In: Natanson M (ed.) Collected Papers, Vol. I: The Problem of Social Reality. The Hague: Nijhoff, pp. 3-47.

Schutz A (1962 [1955]) Symbol, reality and society. In: Natanson M (ed.) Collected Papers, Vol. I: The Problem of Social Reality. The Hague: Nijhoff, pp. 287-356.

Schutz A (1964 [1946]) The well-informed citizen: An essay on the social distribution of knowledge. In: Brodersen A (ed.) Collected Papers, Vol. II. Studies in Social Theory. The Hague: Nijhoff, pp. 120-134.

Schutz A (1970) Reflections on the Problem of Relevance. New Haven, CT: Yale University Press. Thomas WI and Thomas DS (1928) The methodology of behavior study. In: The Child in America: Behavior Problems and Programs. New York: Alfred A. Knopf, pp. 553-576.

Weber M (1978 [1920/21]) Economy and Society: An Outline of Interpretive Sociology. Berkeley: University of California Press.

\section{Author biography}

Jochen Dreher received his MA and PhD in sociology at the University of Konstanz, Germany, where he is now Chief executive officer of the Social Science Archive (Alfred Schutz Memorial Archive) and lecturer in sociology. He is also lecturer in sociology at the University of St. Gallen, Switzerland. His scientific research concentrates on sociology of knowledge, sociology of culture, phenomenology, social theory, qualitative social research, sociology of organization, intercultural communication and the sociological theory of the symbol. His most significant articles include: 'The Symbol and the Theory of the Life-World: The Transcendences of the Life-World and their Overcoming by Signs and Symbols,' published in Human Studies (2003), and 'Phenomenology of Friendship: Construction and Constitution of an Existential Social Relationship,' published in Human Studies (2009). 